\title{
Impact of Religiosity, Africentric Values and Psychological Distress on Adolescent Suicidal Ideation in Ghana
}

\author{
Article by Foster S. Nanewortor \\ B. A., M. Phil, Ghana Police Hospital, Ghana \\ E-mail: makafuibludo@yahoo.com
}

\begin{abstract}
Suicide is a major public health issue in many countries across the globe and Ghana is no exception. As many Western countries have copious amount of research that have help in shedding more light on the phenomenon, very little research on the psychological aspect of suicide has been done in Ghana and other African countries. In order to contribute to the understanding of suicide in Ghana, this research investigated the impact of psychological distress, religiosity and Africentric values/Afrocentrism on adolescent suicidal ideation. Three hundred and eighty-three (383) senior high students between the ages of 13 and 19 years were recruited. The participants completed standardized survey instruments which measured religiosity, psychological distress, Afrocentrism and suicidal ideation. The results showed that higher levels of psychological distress were significantly associated with stronger suicidal ideation. However, this relationship was weakened by the moderation role of the interaction between Afrocentrism and religiosity. It was also discovered that religiosity and Afrocentrism significantly predicted adolescent suicidal ideation. Significant gender differences were established on suicidal ideation. Adolescents who reside in rural areas scored higher on suicidal ideation and psychological distress compared to urban residents. There were no rural-urban differences in adolescents' religiosity and Afrocentrism. The theoretical and practical implications of these findings were discussed.
\end{abstract}

Keywords: Suicide, Suicidal Ideation, Adolescent, Psychological Distress, Religiosity. Africentric/Afrocentric Values.

\section{Introduction}

Seroff (2010) describes suicidal behavior as any deliberate behavior or action with potentially lifethreatening consequences, such as taking a drug overdose, jumping of high heights or deliberately crashing a car. Suicide is ranked one of the top three causes of mortality among adolescences and young adults aged between 15-24 years (Centers for Disease Control and Prevention [CDC], 2006a; Kumar \& Signh, 2006). Globally, an estimated 700,000 people take their own lives annually (Comer, 2007). Almost 1 in 12 adolescents in high school made a suicide attempt, and $17 \%$ of adolescents seriously considered making a suicide attempt in the calendar year 2005 (CDC, 2006b).

Suicide rate in Ghana is very alarming. According to Dali (2009) more than 1556 suicide cases were recorded in 2008. He made this remark during a ceremony to mark the 2009 International Suicide Prevention Day. Further, the 2009 prevalence rate of suicide was estimated to be more than 2150 (Ollenu (2010). This numbers could only be a tip of the iceberg, because till present day, suicidal attempt remains a criminal offence in Ghana according to Section 57 (2) of the Criminal Offences Act 30, 1960. In reference to the criminal offences Act 30,1960, suicidal attempts are likely to attract police arrest and detention in police cells instead of the attempters receiving health professionals' assistance. This could largely be one of the main reasons for the underreporting of suicide especially suicidal attempts in Ghana. Meanwhile, World Health Organization (2012) indicated that "given the magnitude of the public health problem of suicidal behaviors, there is an urgent need for governments to develop a comprehensive national suicide prevention strategy that contextualizes the problem and outlines specific actions that can be taken at 
DOI: $10.21522 /$ TIJPY.2016.02.02.Art002

ISSN: $2518-8852$

multiple levels" (p.7). This means that suicide prevention will remain in a state of inertia if the government of Ghana for instant does not take the deliberate initiative.

The incidence of Suicide is attributable to faulty thinking where attempters believe that by taking their lives they are doing favour to friends and relatives. These irrational beliefs serve as the vein through which suicidal behvaiour occurs (Turecki and Brent, 2016). Suicide gestures and thoughts (suicide ideation) and plans about suicide may reflect pleas for help from people who still wish to live and should not be dismissed lightly. This suggest that suicide is one of the most preventable public health concern globally. According to the International Association for Suicide Prevention ([IASP], 2010 cited in Ollenu, 2010), most of the suicide cases resulted from the complex interaction of casual factors, including mental illness, poverty, substance abuse, social isolation, losses, relationship difficulties and workplace problems.

Scientific/research based information is hardly available in Ghana. In addition to this woe, most of the existing research information on suicide in Ghana delves mainly into attitudes towards suicide and not on the specific factors that may propel or buffer against suicidal behaviors (e.g., Hjelmeland, Akotia, Owens, Knizek, Nordvik, Schroeder, \& Kinyanda, 2008; Osafo, Knizek, Akotia \& Hjelmeland, 2011). Suicide related information mainly exist in the form of media report such as:

A 13-year-old school girl who lived at Anaji Estate, a suburb of Takoradi, has allegedly hanged herself with a sponge. The girl tied the sponge to a metal bar outside a room (Ghanaweb, 2010); Girl, 14, Commits Suicide: what police suspected to be suicide, a 14- year-old girl was found hanging in an abandoned carpenter's shop near her residence in Kumasi. The deceased, Boya Nzor, was a first-year pupil of the Armed Forces Junior High School in Kumasi (Badu, 2010);

According to Otmanns and Emery (1998), suicidal behaviour is the end result of a complex interaction of psychiatric, social and familial factors and there are far more suicidal attempts and gestures than actual completed suicides. It is important to pay close attention to those who make attempts. A suicide has a powerful effect on the individual's family, school and community. We must deal with it as a public health crisis in our schools, clinics and the society in general (Oltmanns \& Emery, 1998).

Research evidence has established that suicidal ideation (thoughts) is closely related to suicide and suicidal behaviour. There is very little information existing on the dynamics of suicide within the Ghanaian population. On many occasions, we read from the papers and hear on the radio or television about people deliberately taking their own lives yet we have very little research publications which seek to identify people at risk of suicide, and how individual handle psychologically distressing situations to prevent themselves from engaging in suicidal behaviors.

The incidence of suicide has grown dramatically since 1955 and is now considered the second leading cause of death among adolescents and young adults worldwide (CDC, 2015). Epidemiological data have also suggested that the transition to adolescence represents a critical developmental vulnerability period for increased suicidal behavior (Prinstein, Simon, Cheah, Nock, Aikins \& Spirito, 2008). Adolescence is also a period of identity formation which is associated with significant psychological distress (Walker \& Townsend, 1999). These identity crises and psychological distress could culminate into what is referred to as suicide crisis. A suicide crisis is one in which the individual is overwhelmed. A person may feel that there are no other options to relieve or reduce the pain felt inside. Often, the person feels limited in options and there is nothing else to do. Sadly, suicidal ideations or thoughts, or attempts are almost always cries for help. The tragedy of the matter is that; it is not everyone who gets the immediate assistance needed. The issue of suicide is largely ignored by many governmental entities responsible for the health and welfare of their citizens. Since little is known about the dynamics of suicide in Ghana, the issue of what causes people to commit suicide for instance is reduced to mere specifications.

Some general community studies by Osafo et al., (2011b, 2012) identified cultural resources including communal family systems and religious group as agents of suicide prevention. There is however no specific research among the Ghanaian adolescents that deals with the extent to which beliefs in African cultural values such as unity and collective responsibility, concern for others and faith in parents and leaders could be used to predict the individuals' suicidal ideation/behaviours. Possible rural and urban differences in 
suicidal behaviours and suicidal ideation among Ghanaian adolescents have also not been investigated. In order to ensure the effective delivery of health-related services to Ghanaian adolescents, it would be important to explore possible rural-urban differences in suicide/suicidal ideation.

It is therefore imperative to investigate any possible link between religiosity, cultural values and reasons for living and adolescent suicidal ideation in Ghana.

Zuraida and Ahmad (2007) for instance assumed that church attendance was synonymous to religious commitment among their participants. This idea is extremely erroneous because mere membership or service attendance does not necessarily mean adherence to the values and teachings of the religious group. Kehoe and Gutheil, (1994) stated that while the literature suggests that religion and spiritual issues are significant and meaningful to many people confronting suicide, studies assessing suicidal risk almost entirely fail to measure specifically religion and spirituality. The current study filled this gap by explicitly investigating the participants' strength of religious faith and how it is related to suicidal ideation.

More so, many previous studies have shed light on the influence of cultural values on the harmful effects of stress (e.g., Belgrave et al., 1997; Jackson et al, 2006) and specifically on the influence of cultural values on suicide/suicidal ideation (e.g., Asante, 1998, 2006; Walker, 2007) among African-Americans. Goldston et al., (2008) have been able to identify the protective aspects within certain cultures that can insulate individuals against suicidal ideation. Asante (2009) also indicated that estrangement from one's own culture practices and values is strongly linked with higher suicidal behaviors. However, some of the studies (e.g., Greening \& Stoppelbein, 2002; Walker \& Bishop, 2005) on cultural differences in suicide/suicidal ideation engaged largely in comparative studies of various ethnic groups such as a comparison of suicide rates of African-Americans and Caucasians. Some of the previous suicidological researches with specific cultural focus have mainly been in the form of quantitative cross-cultural comparisons,

For instance, studies comparing some aspects of suicidal behaviour between a Western and a nonWestern country (e.g., Eshun, 1999; 2003), or, between the majority and a minority population within a country. These comparison may not necessarily investigate the factors within the different cultures that contributes to differences in suicidal behaviours. Walker (2007) for instance, did not state specific beliefs and practices, apart from social support, among African-American which serve as protective factors against suicidal thoughts or behaviors. Another weakness in some of the previous studies is the lack of measurement of specific factors that constitute culture that are likely to influence suicide and suicidal ideation or behaviours. According to Hjelmeland (2010), "many of the numerous risk factor studies conducted in Western countries could be labeled cultural, when surely they are not since the cultural context is most often not explicitly taken into consideration in the analyses" (p. 35).

To understand the complicated and intricate psychology of African people, theory must be created, research must be conducted, and practice must be applied, that are developed out of the experience and worldview of African people (Nobles, 1995; White, 1970). A major justification of the current study is that it investigated specific cultural factors (Africentrism and religiosity) that have been implicated in previous studies as associated with suicidal ideation and or behaviours among adolescents.

Several researches have persistently indicated that there are significant rural-urban differences in suicide/suicidal ideation (e.g., Hirsch, 2006; Ji, Keinman, \& Becker, 2001; Omigbodun, et al., 2008). This research, which also investigated rural-urban differences in suicidal ideation, is able to lay bare the possible rural-urban difference and this would enable a comparison with other countries in the world as well as help in significant decision making to improve public health

In summary, the research investigated the relationship between suicidal ideation and religiosity (in particular religious coping), with a focus on young adults among whom suicidal behaviour is so prevalent. The purpose of the present study is to fill-in the existing gap in terms of how suicidal ideation could be linked with religiosity, Africentrism, and psychological distress among Ghanaian adolescent population.

\section{Aims/objectives of the study}

The following were the aims/objective of the study: 
DOI: $10.21522 /$ TIJPY.2016.02.02.Art002

ISSN: $2518-8852$

To examine whether religiosity serves as a buffer against suicidal ideation among adolescents

Examine the relationship between Africentric values or Africentrism and suicidal ideation

To examine the interaction effect of Africentric values (Africentrism) and religiosity on psychological distress and suicidal ideation ispep:

To investigate how psychological distress can impact on suicidal ideation among adolescents

To find out whether there would be rural-urban difference in suicidal ideation among Ghanaian adolescents.

\section{Hypotheses}

Psychological distress would be positively related to suicidal ideation

There would be a significant negative relationship between religiosity and suicidal ideation

Africentric values/Africentrism would protect adolescents from suicidal ideation

Religiosity and Africentric values would interact to influence the relationship between psychological distress and suicidal ideation

Adolescents who reside in urban areas would score significantly higher on suicidal ideation than participants who reside in rural areas

\section{Methodology}

\section{Participants}

Three hundred and eighty-three (383) adolescents were recruited to participate in the study. This consisted of 182 males and 201 females. Their ages ranged between 13 and 19 years with an average age of 16.46 years with a standard deviation of 1.4. There were participants from all the ten (10) regions of Ghana who reside in various towns and villages. The 383 participants are justified based on the recommendations made by Krejcie and Morgan (1970). According to Krejcie and Morgan (1970), in order to obtain results that are a true representation of the population of about 6000 people, (with $95 \%$ level of confidence), at least 361 participants should be chosen. (Consider consent by parents for children below 18)

\section{Measures}

Four different questionnaires were administered to the participants. These include Africentric Scale (Grills \& Longshore, 1996), Santa Clara Strength of Religious Faith Questionnaire ([SCSRFQ], Plante \& Boccaccini, 1997a), Kessler Psychological Distress Scale ([K10], Kessler, Barker, Colpe, Epstein, Gfroerer, Hiripi et al, 2003) and the Modified Scale for Suicidal Ideation ([MSSI], Miller, Norman, Biship \& Down, 1991). The questionnaires were compiled into a booklet with six sections (A-F) to be completed by the participants. Section A was devoted to demographic characteristics such as age, gender, religious background, etc., of the participants. Sections B, C, D, E and F contained each of the questionnaires: the K10, Africentric Scale, Africentric Scale and MSSI respectively. (The result on Reasons for leaving has been excluded for future further analyses and future publication).

\section{Procedure}

The administration of the questionnaires was done in groups. In all the schools, a special arrangement was made with the school authorities to use one of the classrooms or assembly halls that would ensure that the participants feel comfortable to complete the questionnaires. Participants were first briefed on what the study was about. The briefing was done to ensure a better understanding of the research by the participants. Apart from the briefing which was done by word of mouth, the participants were provided with an information sheet which contained detailed information about the research. After the signing of the informed consent form, the participants were handed the questionnaires to complete. When handed the booklet that contained the questionnaires, they were informed to seek clarification of any questions/statements within the questionnaires that they do not understand. On the average, the participants 
spent between 25-30 minutes to complete. After all the questions were answered, the questionnaires were collected and the participants thanked for their participation. As a sign of appreciation for participating in the study, all participants were presented one (1) of University of Ghana branded pen and pencil.

At the end of each booklet that contained the questionnaires, there was a debriefing sheet. Participants were instructed to detach and read the debriefing sheet. It was indicated in the debriefing sheet that their participation in the research is greatly appreciated.

\section{Ethical concerns}

Permission was obtained from the school authorities and participation in the study was on voluntary basis. Students who volunteered to participate in the study were also presented with informed consent forms to assent to. Participants were also assured of confidentiality. They were further informed of their right to withdraw from the study at any stage of the data collection. They were encouraged to contact their school counselors or any professional if they feel distressed as a result of them recounting their experiences. Alternatively, contacts of some Clinical Psychologists were provided for participants to contact if they so wish.

\section{Data analyses}

The study investigated The Impact of Religiosity, Africentric values, and Psychological Distress on Adolescent Suicidal Ideation in Ghana a total of three hundred and eighty-three (383) senior high school students participated in the study. The data was analyzed using the Statistical Package for Social Sciences (SPSS) version 22.0. The data analyses involved summarizing the data in the form of descriptive statistics (Means and Standard Deviations) and the use of various inferential statistical tests to test the various hypotheses under investigation. A total of five (5) hypotheses were tested. The partial correlation was used to test hypothesis 1,2 and 3 because these hypotheses involved finding the relationship between the variables. Hypothesis 4 was analyzed using Hierarchical Multiple Regression analyses; hypothesis 5 was analyzed using the moderated regression analysis. Finally, Independent samples t test was used to analyze the hypothesis 5 .

\section{Results}

\section{Bivariate analyses of measures}

Pearson Product-Moment correlation was conducted to assess how religiosity, Africentric values, psychological distress and suicidal ideation associate with each other. Variables such as age of respondents, sex of respondents, place of stay of respondents, religion of respondents and history of suicidal attempt were controlled. This is because the literature reviewed has shown that these demographic factors are likely to influence the relationships between the variables under observation. The correlation coefficient observed between each of these variables allow for an evaluation of the degree and direction of association between each pair. Table 1 below presents a summary of the bivariate analyses of the various measures used.

From Table 3, it can be seen that a significant positive correlation was observed between psychological distress and suicidal ideation $[\mathrm{r}(381)=.37, \rho<0.01]$. This means that higher level of psychological distress is associated with increasing level of suicidal ideation and vice versa. This confirms the hypothesis which predicted that psychological distress would be positively related to suicidal ideation.

The correlation observed between religiosity and suicidal ideation was negative and significant $[\mathrm{r}$ (381) $=-0.287, \rho<0.01]$. This means that higher level of religiosity was associated with decreasing suicidal ideation. It implies that hypothesis 3 which stated that there would be a significant negative relationship between religiosity and suicidal ideation was confirmed by the results. Furthermore, the correlation observed between Africentric values and suicidal ideation was negative and significant $[\mathrm{r}(381)=-0.211$, $\rho<0.01]$. This is interpreted to mean that higher level of Africentric values was associated with lower suicidal ideation and vice versa. It implies that third hypothesis which stated that Africentric values would protect individuals from suicidal ideation was supported by the results obtained. 
DOI: $10.21522 /$ TIJPY.2016.02.02.Art002

ISSN: $2518-8852$

Interaction Effect of Religiosity and Africentrism on the Relationship between psychological distress and Suicidal Ideation.

It was hypothesized that religiosity and Africentric values would interact to influence the relationship between psychological distress and suicidal ideation. The Hierarchical Multiple Regression was used to test this hypothesis. This method was used in order to determine the extent to which of the following variables religiosity, Africentric values and psychological distress predicts suicidal ideation. The results obtained are presented in the Table 2.

From Table 2, it can be observed that psychological distress had a significant influence on suicidal ideation $[\mathrm{F}(1,381)=92.46, \rho=0.001],(\beta=.442, \rho<0.001)$. The model 1 indicated that psychological distress accounted for $19.5 \%$ of variance in suicidal ideation. It is observed that religiosity $[\mathrm{F}(1,381)$ $=73.325, \rho=0.001],(\beta=.292, \rho<0.001)$ and Africentric values had significant influence on psychological distress significantly influence suicidal ideation $[\mathrm{F}(1,381)=50.478, \rho=0.001],(\beta=.091, \rho<0.05)$. The model 2 indicated that religiosity accounted for $8.3 \%$ of the variance in suicidal ideation while model 3 indicated that Africentric values accounted for .7\%.

Upon introduction of the interaction between religiosity and Africentric Values in the model 3, the fit of the model increased $[F(1,380)=37.769, \rho=0.001],(\beta=.108, \rho<.05)$. The model 4 indicated that the interaction between religiosity and Africentric values accounted for $2.1 \%$ variance in suicidal ideation. This means that the interaction between religiosity and Africentric values significantly influence the strength of the relationship between psychological distress and suicidal ideation. This confirmed the hypothesis four which stated that religiosity and Africentric values would interact to influence the relationship between psychological distress and suicidal ideation.

Rural-Urban Differences in suicidal ideation, Psychological Distress, Religiosity and Africentrism.

It was predicted in this research that adolescents who reside in urban areas would score significantly higher on suicidal ideation than adolescents who reside in rural areas. The hypothesis was tested using the independent $t$ test because it involves the comparison of suicidal ideation of two independent samples (rural residents and urban) on suicidal ideation. The results obtained from the analyses are presented in Table 3 below.

From the Table 3 above it can be observed that the independent $t$ value obtained was significant $[t$ (381) $=3.533, \mathrm{p}=0.001]$. This implies that a significant difference exists between the suicidal ideation reported by rural and urban residents. It can be observed from the Table 3 that rural residents obtained higher suicidal ideation scores $(M=8.52, S D=9.08)$ than urban residents $(M=5.62, S D=6.89)$. This observation means that the hypothesis 8 which stated that adolescents who reside in urban areas would score significantly higher on suicidal ideation than participants who reside in rural areas was not confirmed by the results.

Rural residents scored significantly higher on psychological distress compared to urban residents. Rural residents scored significantly higher on psychological distress compared to urban residents. However, adolescents who live in rural and urban areas do not differ in Africentrism [ $\mathrm{t}(381)=0.381, \mathrm{p}=.35$ ], and religiosity [t $(381)=0.447, \mathrm{p}=.32]$.

\section{Discussion}

The results from the study were revealing and interesting in many respects. The results showed that higher scores on psychological distress were associated with higher scores on suicidal ideation. Furthermore, it was observed that higher scores on Africentric values and religiosity were significantly associated with lower scores on Suicidal Ideation.

In addition, it was observed that religiosity and Africentrism interacted significantly to reduce the strength of relationship between psychological distress and suicidal ideation. Significant rural-urban differences were found in religiosity, Africentrism, and psychological distress. Adolescents who reside in rural areas were found to score significantly higher on psychological distress and suicidal ideation than adolescents who reside in urban areas. On the other hand, urban adolescents had significantly higher reasons 
for living than rural adolescents. There were however no rural-urban differences in religiosity and Africentrism.

\section{Psychological distress and suicidal ideation}

It was predicted that psychological distress would be positively related to suicidal ideation. This prediction was confirmed by the results obtained. Results observed showed that higher level of psychological distress was positively and significantly associated with higher level of suicidal ideation. Psychological distress in itself is accompanied by uneasy feelings of anxiety or depression in response to specific demands that results from temporary or permanent changes that may be harmful. The symptoms of psychological distress include feelings of sadness; need for the help of others to make decisions, troubles sleeping and difficulty coping with everyday problems. Psychological distress therefore may give an indication of anxiety or depressive disorders. Once the adolescents' judgment is impaired, as a result of the distress they experience, they may tend to see death as the only exit. Lester (2000) stated that suicidal individuals are people who are exposed to chronic stress for a long period of time. Chronic stress in itself is likely to come with associated psychological distress. The current finding is in agreement with the psychiatric/psychological disturbances theory of suicide which stated that psychiatric disturbances are the strongest predictors of future suicidality (Maris, Berman, \& Silverman, 2000). Closely related to this theory is the diathesis-stress model of suicidality proposed by Mann, Oquendo, Underwood and Arango (1999) which portends that an individual is especially vulnerable to later attempting suicide in the future because psychiatric/psychological illness may act as a stressor that potentiates suicide crisis.

Furthermore, the current result provides empirical support to the theory of psychache propounded by Shneidman (1993). From his clinical experience and research, Shniedman (1993) indicated that all suicides are a direct result of immense psychological pain, or what he referred to as psychache.

The state of psychological distress, together with one's inability to tolerate the psychological pain, and cognitive constriction leads to the point where suicide is seen as the only means of escape. This is likely to explain why higher score on psychological distress is associated with higher suicidal ideation. As a result of the higher psychological distress, these adolescents develop certain associated psychological disorders which are likely to affect both their physical as well as mental health and hence deplete their reasons to stay alive.

Additionally, the current finding that higher suicidal ideation is associated with higher psychological distress is congruent with the results obtained by Cross, Gust-Brey and Ball (2002); Koutek, Kocourkova, Hladikova and Hrdlicka (2009); McKelvey, Davies, Pfaff, Acres and Edwards (1998); Page and West (2011).

\section{Religiosity and suicidal ideation}

It was hypothesized that there would be a significant negative relationship between religiosity and suicidal ideation. Results obtained from the analyses supported this prediction. The results showed that higher scores on religiosity were significantly associated with lower scores on suicidal ideation. This implies that adolescents with high religiosity are less likely to express suicidal ideations and vice versa. It is important to remember here that religiosity as operationally defined by this study implies the strength of the adolescents' religious faith. This measures the extent to which the adolescent respondents believed their religious faith served as a source of inspiration and comfort and also the extent to which their religious faith is important to them and how actively they participate in their religion. The inverse relationship observed between religiosity and suicidal ideation could be explained from the view point that religiosity served as a protective factor that cushions adolescents against suicidal ideation. The current findings are consistent with what was found by previous researches among clinical samples (e.g., Hassan, Anam \& Rakshanda, 2016; Zuraida \& Ahmad, 2007) and general populations (e.g., Lester, 1991; Greening \& Stoppelbein, 2002; Sean, 2011; Walker \& Bishop, 2005). Hassan, Anam and Rakshanda (2016) for instant observed religiosity as a strong positive predictor of mental wellbeing which in turn has strong linkages with suicidality. 
DOI: $10.21522 /$ TIJPY.2016.02.02.Art002

ISSN: $2518-8852$

\section{Africentric values and suicidal ideation}

The research hypothesis which predicted that Africentric values would protect adolescents against suicidal ideation was confirmed. Results obtained indicated that higher scores on Africentric values scale were significantly associated with lower scores on suicidal ideation. This means that the more the adolescent participants were entrenched in African centred values, the less likely they are to have suicidal thoughts. The Africentric values or what is also referred to as Africentrism was measured by seven principles which were established to be common to African people (Whitlow, 2006). Ashanti's (2009) research also lent massive support to the current findings. Ashanti indicated that the more blacks become estrange from their own culture the more their suicide rates. Cultural estrangements may leave the adolescents vulnerable and this would pose challenges to their problem solving abilities and general adjustments. This finding is also consistent with the observations of Osafo and Akotia (2014).

\section{Rural and urban differences in suicidal ideation}

It was hypothesized that adolescents who reside in urban areas would score significantly higher on suicidal ideation than participants who reside in rural areas. Result from the analyses does not support this hypothesis. The results showed that the adolescents who reside in rural areas scored significantly higher on suicidal ideation than those who reside in urban areas. It is interesting to note that significant rural-urban differences were also found in psychological distress. In fact, rural adolescents were found to experience higher psychological distress. It is therefore in place to conclude that the stronger suicidal ideation experiences by rural adolescents could be linked with their experience of higher psychological distress. This observation may result from the fact that there is limited access to health facilities, counselors, psychologists and other health professionals in rural areas who could offer services that can help in dealing with psychological distress. Consequently, rural adolescents may not be able to access the necessary professional services that can help to improve their physical and psychological health. Rural adolescents may also not be able to get the necessary guidance and counseling which may be needed to deal with massive physiological and emotional changes that occur during adolescence. The above listed problems coupled with stiffer parental controls (Ganong, Coleman, Beckmeyer, Benson, Jamison, McCaulley \& Sutton, 2007) may lead to constricted ideas in which rural adolescents may start to have suicidal thoughts. Ganong, and colleagues stated that as a result of differing infrastructures, economies, and community values and beliefs, rural and urban parents approach their role as parents differently and that rural parents tend to be more controlling of their children instead of guiding and monitoring them.

The current result provides empirical support to the findings of earlier studies (American Association of Suicidology, 1998; Hirsch, 2006). Hirsch's (2006) meta-analyses of studies indicated that suicide is a public health issue in rural areas, with suicide rates often greater than what is observed in urban areas. On the contrary, the finding of the present study was done by Omigbodun, Gogra, Esan and Adedokun (2008) who found that urban adolescents had higher rates of suicidal behavior than adolescents from rural areas in Southern Nigeria. However, a major flaw however in Omigbodun and colleagues study was that they employed descriptive statistics in their data analyses process and hence makes it difficult for inferences to be made from their results.

\section{Observed model}

The findings have been summarized in a model which has been illustrated illustrated in Figure 1. The model illustrates how psychological distress, Africentrism and religiosity are related to suicidal ideation among adolescents. From the 1, it can be observed psychological distress, Africentric values and religiosity predict suicidal ideation. Furthermore, the place of residence of the respondents influences the levels of psychological distress and suicidal ideation. It also indicates the linkage between religiosity and Africentric values and their influence on the relationship between psychological distress and suicidal ideation. 


\section{Conclusions}

The findings indicate that this study has been able to successfully achieve its aims/objectives. It is clear from the findings that higher psychological distress is likely to predict strong suicidal ideation among adolescents. Furthermore, stronger religious faith or frequent religious coping is able to predict lower suicidal thoughts among adolescents.

From these findings, it can be concluded that higher levels of religiosity and Africentric values/Africentrism are likely to significantly prevent adolescent from having suicidal thoughts. Client management strategies that aim at identifying psychological distress as well as increasing religiosity, Africentrism and in adolescents therefore have the potential of preventing suicide. Therapists, guidance and counselling officers, clinical psychologists and other professionals who deal with the management of suicide crises for instance, can focus on reducing psychological distress while strengthening values of communality, concern for others which are parts of Africentric values/Africentrism and also religiosity in their clients for effective positive outcomes.

\section{Figures and tables}

Table 1. Summary of correlations observed between religiosity, africentric values, psychological distress and suicidal ideation $(\mathrm{df}=381)$

\begin{tabular}{|c|c|c|c|c|}
\hline Variables & $\begin{array}{l}\text { Suicidal } \\
\text { Ideation }\end{array}$ & Religiosity & $\begin{array}{l}\text { Psychological } \\
\text { Distress }\end{array}$ & $\begin{array}{l}\text { Africentric } \\
\text { Values }\end{array}$ \\
\hline Suicidal ideation & - & & & \\
\hline Religiosity & $-.287 * *$ & - & & \\
\hline $\begin{array}{l}\text { Psychological } \\
\text { Distress }\end{array}$ & $.37 * *$ & $-.089 *$ & - & \\
\hline Africentric Values & $-.211^{* *}$ & $.392 * *$ & -.043 & - \\
\hline
\end{tabular}

Table 2. Summary of results on the moderation effect of the interaction between religiosity and africentric values on the relationship between psychological distress and suicidal ideation $(n=383)$

\begin{tabular}{lllll}
\hline Model & & B & SE B & $\beta$ \\
\hline 1 & (Constant) & -5.058 & 1.277 & \\
& Psychological Distress & .507 & .053 & $.442^{* *}$ \\
& (Constant) & 16.529 & 3.479 & \\
& Psychological Distress & .456 & .051 & $.397^{* *}$ \\
& Religiosity Score & -.578 & .087 & $-.292^{* *}$ \\
& (Constant) & 20.457 & 4.019 & \\
& Psychological Distress & .454 & .050 & $.395^{* *}$ \\
& Religiosity Score & -.507 & .095 & $-.256^{* *}$ \\
& Africentric Score & -.130 & .067 & $-.091^{*}$ \\
& (Constant) & 20.185 & 4.323 & \\
& Psychological Distress & .453 & .051 & $.395^{* *}$ \\
& Religiosity Score & -.500 & .103 & $-.252^{* *}$ \\
& Africentric Score & -.129 & .067 & -.091 \\
& Interaction(Religiosity & .192 & .034 & $.108^{*}$ \\
& and Africentrism) & & \\
\hline
\end{tabular}

$\mathrm{R} 2=.195$ for step $1 ; \Delta \mathrm{R} 2=.083$ for step $2 ; \Delta \mathrm{R} 2=.007$ for step $2 ; \Delta \mathrm{R} 2=.021$ for step $4 ; * \mathrm{p}<.01 ; * * \mathrm{p}<.001$ 
DOI: $10.21522 /$ TIJPY.2016.02.02.Art002

ISSN: $2518-8852$

Table 3. Summary of independent $t$ test of rural-urban differences in suicidal ideation, psychological distress, religiosity and africentrism ()

\begin{tabular}{|c|c|c|c|c|}
\hline Variable & $\begin{array}{l}\text { Place of Stay } \\
\text { Rural } \\
(\mathrm{n}=145) \\
\text { Mean (SD) }\end{array}$ & $\begin{array}{l}\text { Urban } \\
(\mathrm{n}=238) \\
\text { Mean (SD) }\end{array}$ & $\mathrm{t}$ & $\mathrm{p}$ \\
\hline Suicidal Ideation & $8.52(9.08)$ & $5.62(6.89)$ & 3.533 & $.001^{*}$ \\
\hline Psychological distress & $24.00(6.45)$ & $22.72(7.11)$ & 1.77 & $.04 *$ \\
\hline Africentric Values & $49.19(5.52)$ & $49.42(5.60)$ & 0.381 & .35 \\
\hline Religiosity & $35.41(3.73$ & $35.21(4.15)$ & 0.447 & .32 \\
\hline
\end{tabular}

*Significant at 0.05 level of significance

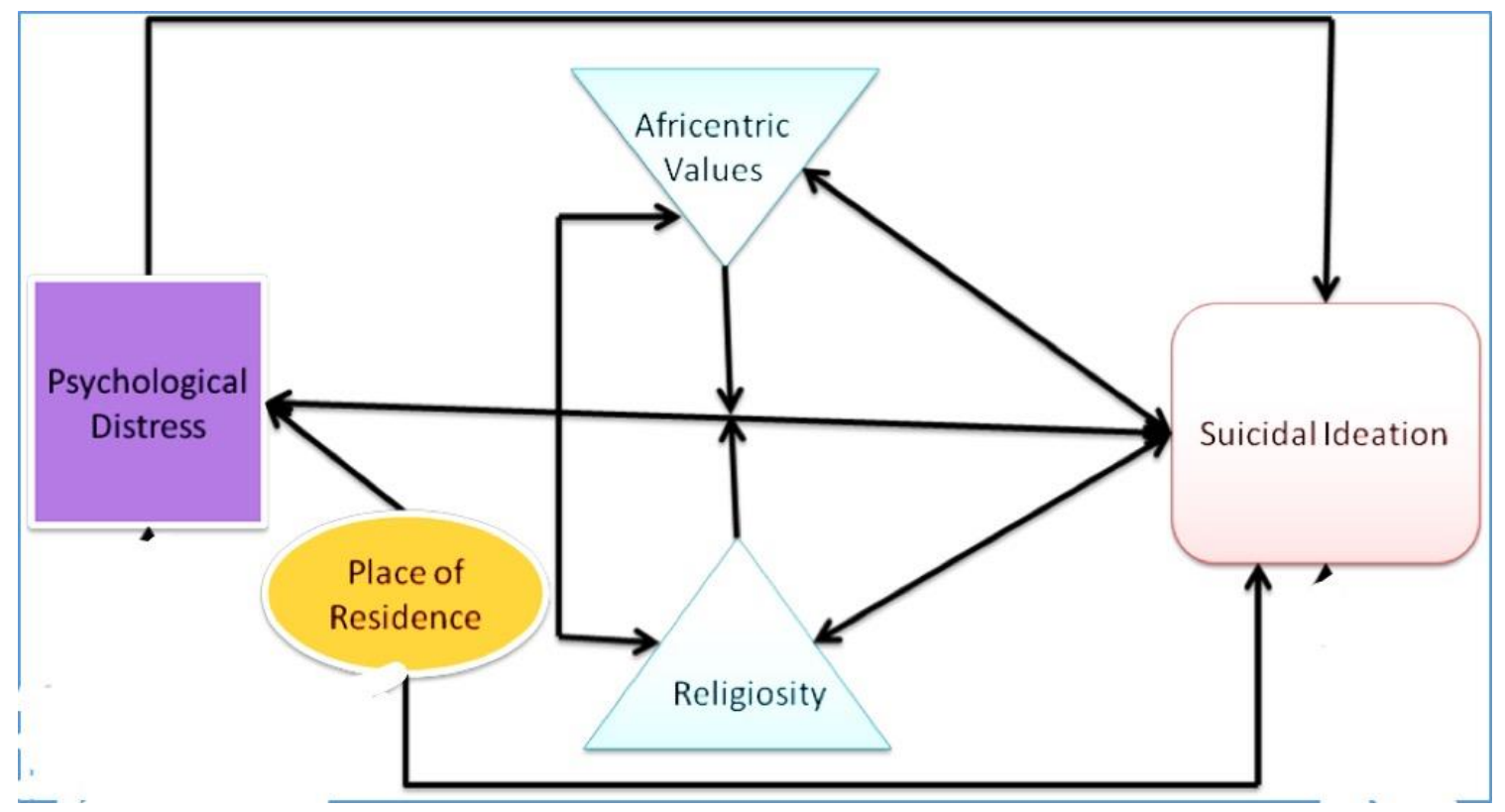

Figure 1. A model illustrating the observed impact of reasons for living, religiosity, africentric values, psychological distress, place of residence and gender on suicidal ideation among adolescents.

\section{Acknowledgments}

I give due acknowledgement to Emeritus Prof. C.C Mate, Prof Charity S. Akotia and Dr E. Sampong for their support through this study.

\section{References}

[1]. American Association of Suicidology. (1998). School suicide prevention guide- lines. Washington, DC: Author.

[2]. Asante, M. K. (1987). The Afrocentric Idea. Philadelphia: Temple University Press.

[3]. Asante, M. K. (1998). The American mode of transcendence (pp. 295-301). In G. Jennings, Passages beyond the gate: A Jungian approach to understanding the nature of American psychology at the dawn of the new millennium. Needham Heights, MA: Simon \& Schuster Custom Publishing.

[4]. Asante, M. K. (2006). The rhetoric of globalization: Europeanization of human ideas. Journal of Multicultural Discusses, 1(2):152-8.

[5]. Beck, A. T. (1963). Thinking and depression: Idiosyncratic content and cognitive distortions. Archives of General Psychiatry, 9: 324-333isepi:Beck, A. T., Kovacs, M. \& Weissman, A., (1979). Assessment of suicidal intention: the Scale for Suicide Ideation. Journal of Consulting Clinical Psychology, 47:343-352. 
[6]. Belgrave, F. Z., Townsend, T.G., Cherry, V. R., Cunningham, D. M. (1997). The influence of an Africentric worldview and demographic variables on drug knowledge, attitudes, and use among African American youth. Journal of Community Psychology25:421-433.

[7]. Centers for Disease Control and Prevention (2006a). Welcome to WISQARS (Web-based Injury Statistics Query and Reporting System). Retrieved September, 16th 2016, from Centers for Disease Control and Prevention, National Center for Injury and Prevention Control Web site: http://www.cdc.gov/ncipc/wisqars/

[8]. Centers for Disease Control and Prevention (2006b). Youth Risk Behavior Surveillance-United States, 2005. Morbidity and Mortality Weekly Report: Surveillance Summary, 55(5), 1- 108.

[9]. Centers for Disease Control and Prevention (2015). Mortality and Mortality Weekly Report, Suicide Trends among Persons Aged 10-24 Years, 1994-2012. Access from www.cec.gov/mmwr on September, 15th 2015.

[10]. Dali, M. (2009). Suicide in Ghana. Accessed on December, 215 from www.modedernghana.com.

[11]. Durkheim, E. (1951). Le Suicide. Translated by J. Spaulding and G. Simpson. Glencoe, IL: Free Press.

[12]. Durkheim E. (2002). Suicide. London: Routledge Classics.

[13]. Erikson E.H., (1968). Identity Youth and Crisis. New York: W. W. Norton \& Company Eshun, S., (1999). Cultural Variations in Hopelessness, Optimism, and Suicidal Ideation: A Study of Ghana and U.S. College Samples. Cross-Cultural Research, 33(3), 227- 238.

[14]. Eshun, S. (2003). Sociocultural Dete, rminants of Suicide Ideation: A Comparison Between American and Ghanaian College Samples. Suicide and Life-Threatening behaviour, stspe 3 (2); 165-171.

[15]. Foley, D. L., Goldston, D. B., Costello, E. J., \& Angold, A. (2006). Proximal psychiatric risk factors for suicidality in youth: The Great Smoky Mountains Study. Archives of General Psychiatry, 63:1017 24.

[16]. Ghanaweb, (2010). Girl, 13, Commits Suicide. General News of Friday, 17 September 2010. Retrieved on 19th September, 2010, from www.ghanaweb.com/GhanaHomePage/NewsArchive/artikel.php?ID=190545

[17]. Ganong, L., Coleman, M., Beckmeyer, J., Benson, Jamison, T., McCaulley, G., \& Sutton, E. (2007). Poverty in American: Rural and urban differences (Research Brief). Columbia: University of Missouri, Human Environmental Sciences Extension.

[18]. Goldston, D. B., Molock, S. D., Whitbeck, L. B., Murakami J. L., Zayas, L. H, \& Hall, G. C. (2008). Cultural considerations in adolescent suicide prevention and psychosocial treatment. The American Psychologist, 63 (1):1431.

[19]. Greening L. \& Stoppelbein L. (2002). Religiosity, attributional style, and social support as psychosocial buffers for African American and White adolescents' perceived risk for suicide. Suicide Life-Threat. 3:404-417.

[20]. Grills, C. \& Longshore, D. (1996). Africentrism: Psychometric analyses of a self-report measure. Journal of Black Psychology, 22(1), 86-106.

[21]. Hassan, R, Anam, Y. \& Rakshanda, R. (2016). Religiosity in relation with psychological distress and mental wellbeing among Muslims. International Journal of Research Studies in Psychology, 5 (2): 65-74.

[22]. Hilton, S. C., Fellingham, G. W. \& Lyon, J. L. (2002). Suicide Rates and Religious Commitment in Young Adult Males in Utah. American Journal of Epidemiology, 155 (5): 413-419

[23]. Hirsch, J. K. (2006). A review of the literature on rural suicide: Risk and protective factors, incidence and prevention. Crisis: The Journal of Crisis Intervention and Suicide Prevention, 27, 189- 199. doi:10.1027/02275910.27.4.189.

[24]. Hjelmeland, H. (2010). Cultural Research in Suicidology: Challenges and Opportunities. Suicidology Online, $1: 34-52$.

[25]. Hjelmeland, H., Akotia, C. S., Owens, V., Knizek, B. L., Nordvik, H., Schroeder, R., \& Kinyanda, E., (2008). Self-reported suicidal behavior and attitudes toward suicide and suicide prevention among psychology students in Ghana, Uganda, and Norway. Crisis, 9(1), 20-31.

[26]. Jackson, F., Morrant, M., Hall, B., Moscovitz, N. et al (2006). Natioanal Guidelines on Suicide. Retrieved from http://www.ccsmh.ca/en/projects/suicide.cfm, on 24th January, 2015.

[27]. Kessler, R.C., Borges, G \& Walters, E.E (1999). Prevalence of and risk factors for lifetime suicide attempts in the National Comorbidity Survey. Archives of General Psychiatry, 56:617-626. 
DOI: $10.21522 /$ TIJPY.2016.02.02.Art002

ISSN: $2518-8852$

[28]. Kessler, R. C., Barker, P. R., Colpe, L.J, Epstein, J. F., Gfroerer, J. C., Hiripi, E., et al. (2003). Screening for serious mental illness in the general population. Archives of General Psychiatry, 60(2):184-9.

[29]. Kehoe NC, Gutheil TG (1994), Neglect of religious issues in scale-based assessment of suicidal patients. Hosp Community Psychiatry 45(4):366-369.

[30]. Kumar, B. \& Signh, R. (2006). Suicide Ideation and Psychopathology among Adolescents. Europe's Journal of Psychology, 2 (8): 1-13.

[31]. Lester, D. (1991). The Study of Suicidal Lives. Suicide and Life-Threatening Behavior, 21 (2):164-173.

[32]. Liu, X., Sun, Z., \& Yang, Y. (2008). Parent-reported suicidal behavior and correlates among adolescents in China. Journal of Affective Disorders, 105: 73-80

[33]. Miller, I. W., Norman, W.H., Bishop, S. B., \& Dow, M. G. (1991). The Modified Scale for Suicidal Ideation: Reliability and validity. Journal of Consulting and Clinical Psychology, 54, 724-725.

[34]. Myjoyonline (2009). Editorial: 1,556 Suicides in 2008. Retrieved on 22nd September, 2015 from http://news.myjoyonline.com/features/200909/35215.asp.

[35]. Neuringer, C. (1964). Rigid thinking in suicidal individuals. Journal of Consulting Psychology, 24: 54-58.

[36]. Ollenu, R. (2010). Ghana: Suicide rate hits alarming proportions. Accessed on 20th November, 2016 from http://allafrica.com/stories/201001181271.html (accessed 8/12/201).

[37]. Oltmanns, T. S. \& Emery, R.E. (1998). Abnormal Psychology (2nd Ed.). Prentice Hall Inc., New Jersey. [38]. Omigbodun, O., Dogra, N., Esan, O., \& Adedokun, B., (2008). Prevalence and Correlates of Suicidal Behaviour among Adolescents in Southwest Nigeria. International Journal of Social Psychiatry, 54(1) 34-46.

[39]. Osafo, J. \& Akotia, C. S. (2014). Suicidal behavior in Ghana, In C.S. Akotia and C. C. Mate-Kole, (Eds) Contemporary Psychology: Readings from Ghana, p.131-144.

[40]. Osafo, J., Hjelmeland, H., Akotia, C.S. \& Knizek, B. L. (2011b). The Influence of Religious factors on Attitudes towards Suicidal Behavior in Ghana. Journal of Religion and Health. DOI10.1007/s10943-011-9487-3.

[41]. Osafo, J., Knizek, B. L. Akotia, C.S. \& Hjelmeland, H. (2012). Attitudes of psychologys and nurses towards suicide and suicide prevention in Ghana: A qualitative study. International Journal of Nursing Studies, 49, 691-700.

[42]. Plante, T.G. \& Boccaccini, M.T. (1997a). The Santa Clara Strength of Religious Faith Questionnaire. Pastoral Psychology, 45, 375-387.

[43]. Plante, T.G. \& Boccaccini, M.T. (1997b). Reliability and validity of the Santa Clara Strength of Religious Faith Questionnaire. Pastoral Psychology, 45, 429-437.

[44]. Plante, T.G., Yancey, S., Sherman, A., Guertin, M. \& Partdini, D. (1999). Further validation for the Santa Clara Strength of Religious Faith Questionnaire. Pastoral Psychology, 48, 11- 21.

[45]. Prinstein, M.J., Simon, V., Cheah, C. L. S. Nock, M.K., Aikins, J. W. \& Spirito, A., (2008). Longitudinal Trajectories and Predictors of Adolescent Suicidal Ideation and Attempts Following Inpatient Hospitalization. Journal of Consulting and Clinical Psychology, 76(1): 92-103.

[46]. Shneidman, E. S. (1980). A possible classification of suicidal acts based on Murray's need system. Suicide and Life-Threatening Behavior, 10; 175-181

[47]. Shneidman, Edwin S., (1981). Orientations toward Death: Sub-intentioned Death and Indirect Suicide. Suicide and Life-Threatening Behavior 11(4); 232-253

[48]. Shneidman, E. S. (1992). What do suicides have in common? Summary of the psychological approach. In B.

Bongar (Ed.), Suicide: Guidelines for assessment, management, and treatment (pp. 3-15). New York: Oxford University Press.

[49]. Turecki, G. \& Brent, D. A. (2016). Suicide and suicidal behavior. Lancet, 19: 1227-1239.

[50]. Walker, R. L. (2007). Acculturation and acculturative stress as indicators for suicide risk among African Americans. American Journal of Orthopsychiatry, 77 (3): 386-9.

[51]. Walker, R. L., \& Bishop, S. (2005). Examining a model of the relation between religiosity and suicidal ideation in a sample of African American and White college students. Suicide \& Life- Threatening Behavior, 35(6), 630-639. [52]. Whitlow, N. M. (2006). The development and validation of the whitlow Measure of Afrocentric relationship attitudes. A Dissertation Presented to the Faculty of the Graduate School University of Missouri-Columbia. Retrieved on the 6th April 2015 from 
https://mospace.umsystem.edu/xmlui/bitstream/handle/10355/4396/research.pdf?sequence=3

[53]. World Health Organization (1999). Figures and facts about suicide. Geneva: WHO

[54]. World Health Organization (2012). Public health actions for the prevention of suicide: a framework. Geneva: WHO Document Production Services.

[55]. Zuraida N.Z., and Ahmad H.S., (2007). Religiosity and Suicide Ideation in Clinically Depressed Patients. Malaysian Journal of Psychiatry, 16 (1): 254-316. 